\title{
CREATING SMART HEALTH SERVICES USING NLP TECHNIQUES
}

\author{
Aldina Avdić ${ }^{*}$, \\ Ulfeta Marovac ${ }^{1}$, \\ Dragan Janković
}

\author{
${ }^{1}$ Department for Technical Sciences, \\ State University of Novi Pazar, \\ Novi Pazar, Serbia \\ ${ }^{2}$ Faculty of Electronic Engineering - \\ University of Nis, \\ Nis, Serbia
}

\begin{abstract}
:
The rapid growth of the urban population and the development of information and communication technologies have led to the creation of a new concept - a smart city. The smart city uses information and communication technologies to improve the quality of life of its citizens. One of its most important components is smart health. Also, heaps of textual data are created every day, in medical information systems, then there are the government documents, and citizens' comments, reviews, etc. This paper examines the possibility of using text mining techniques and natural language processing to create smart health services. Three services intended for these purposes have been proposed, designed, and implemented: a service for answering patients' questions, an information board for visualizing data about an epidemic, and automatic processing of questionnaires and psychological tests.
\end{abstract}

\section{Keywords:}

Smart Health Services, Natural Language Processing, Text Mining.

\section{INTRODUCTION}

The constant progress of information and communication technologies (ICT) has enabled their application in almost all segments of individuals' lives to provide many services which make life easier for citizens. Modern technological infrastructure (Internet, smartphones with built-in sensors, smart devices in the household) is available today to most of the population. Techniques for processing large amounts of data, collective intelligence, and increasing the number of inhabitants in urban areas enabled the creation of a smart city, which is efficient in terms of energy consumption, transport, administration, learning, economic development, and other aspects [1]. It is based on Big Data [2] and IoT technologies [3]. Within the smart city, there are smart transport, smart agriculture, smart administration, smart education, smart healthcare, etc. Smart health uses ICT technologies to create services which contribute to the facilitation of medical procedures and better health of the population [4].
Correspondence:

Aldina Avdić

e-mail:

apljaskovic@np.ac.rs 
The difference between e-health and smart health is in the flow of data. For example, creating electronic reports using the medical information system is an example of e-health, but enabling communication with doctors, and dashboard with analysis based on data in medical information systems (where the data flow is from citizens to smart city, and from smart city to citizens), are examples of using smart health.

Large amounts of data are collected daily, in medical information systems, then there are documents related to the medical domain (instructions for medicines, various forums containing instructions of experts, etc.).

Some information from patients can be collected using crowdsourcing (the technique of acquiring knowledge through the voluntary participation of users) [5]. EHRs [6] are electronic medical records created and stored in medical information systems and contain information about the patient's examination. They contain structural fields, such as name, identification number, date of examination, location of the institution where the examination was performed, diagnosis code, name of the diagnosis, but also contain a non-structural part consisting of physician observations that cannot be expressed through structural fields, physician notes, diagnoses, laboratory results, therapies, etc. The documents also contain textual data, as the free-answer questions in the questionnaires for patients. Unstructured data must be organized and structured in a way that allows their analysis. This requires sophisticated statistical and linguistic techniques. This process is usually associated with the artificial intelligence (AI) technique called natural language processing (NLP), which allows the system to understand the meaning of data in human language. The goal of NLP is to read, decipher, understand, and find meaning in natural language. Most NLP techniques rely on machine learning to infer the meaning of data in natural languages [7].

The research question of this paper is whether and how NLP techniques can be used to create smart health services. The motivation for this research is the creation of smart health services based on NLP which would be useful for patients and citizens in a smart city. For the realization of this research, the method of description was applied to the existing smart health services based on NLP techniques. Three services are proposed and using the modeling method and use case diagrams are shown. Details of the implementation and a screenshot of the demo systems that implement these services are given.
The paper is organized as follows. The second section presents the application of NLP techniques for medical purposes through related research. This is followed by a proposal and a description of NPL-based health services, and the implementation of the service is given. In the end, the conclusion and directions of further research are given.

\section{RELATED WORK}

This section presents research and examples of the use of tools based on NLP techniques for improving health. One of the ways to use the processing of textual data entered by users is the detection of depression [8].

The most popular medical text marking systems are CTAKES and CLAMP systems [9] [10]. The identification of medical terms in texts written by patients, using crowdsourcing, is presented in [11]. One approach to correcting errors in the free text of medical reports is presented [12].

\section{SMART SERVICES BASED ON NLP TECHNIQUES}

This section describes services based on NLP. The source of data for the implementation of these services are documents written in natural languages, citizens' answers obtained by crowdsourcing and EHRs from medical information systems. The service whose input data are documents is used to answer patients' questions. The service whose input data are the answers of citizens obtained by filling out questionnaires is the automatic processing of psychological tests. The service that processes the data entered in the EHRs displays data on the state of the epidemic. Use case diagrams, a description of the services, and finally presentations of their implementation are given.

\subsection{ANSWERING THE PATIENTS' QUESTIONS}

The smart health service for automatic answering of questions and search of medical documents should provide the user to enter a question and get an answer based on the similarity with the sentences in medical documents entered in the system by experts. The capabilities of this service are shown by the use case diagram used in Figure 1. 


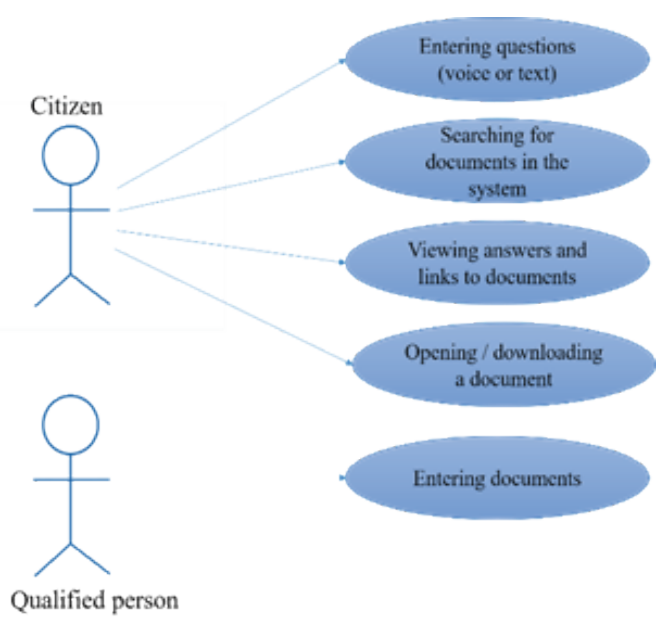

Figure 1. Use case diagram for the service for the automatic answering of citizens' questions

This service should help the citizen to get an answer to his question quickly at any time. There are three types of content in the system: questions, formal documents, and expert answers. Questions and documents are grouped based on keywords. When the user asks a new question, its similarity with the questions and documents in the selected group is considered. Preparation of documents for processing, normalization, extraction of keywords, the grouping of the documents and questions as well as finding the answer to the question are NLP techniques necessary for the realization of this service [13].

\section{Postavite pitanje

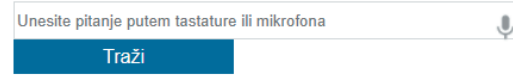 \\ Najčešća pitanja \\ bolovi u mišićima povišena telesna temperatura \\ bolovi u mišićima \\ andol.txt. \\ Figure 2. The realization of service for answering patient's questions}

Figure 2 shows the realization of the client part of the document search service, i.e., answering citizens' questions.
The question can be entered directly from the keyboard or by voice, where the voice is recognized and converted to text, using the Speech to Text API [14], for automatic speech recognition in Serbian. It is also possible to click on one of the most frequently asked questions, and search for it. The result is a document containing an answer to a question.

On the server-side, an expert can enter a document in $p d f, t x t, d o c$, and $d o c x$ format, after which the documents are normalized and stored in the database in a searchable form. When entering a document, the keywords for the document are automatically extracted, however, they can also be entered by the expert who enters the document, to further enrich the metadata.

\subsection{AUTOMATIC PROCESSING OF QUESTIONARIES}

Psychological tests often limit the respondent by offering him the possibility of choosing some of the offered options without entering a free answer because it is complicated for analysis. For the realization of the service for automatic processing of questionnaires and psychological tests, it is necessary to collect information about the mental state, as well as about specific reactions to appropriate stressful situations.

The questions are expressed in the form of standardized psychological tests as well as fields for describing a stressful situation. The frequency of similar stressful situations, as well as evoked feelings in comparison with the results obtained from psychological tests, can more clearly indicate the existence or non-existence of a corresponding psychological problem. A person best describes his mental state in his mother tongue, so the analysis of these tests is adapted to people who speak Serbian. The complexity of processing texts in the Serbian language is an additional challenge. This service can be applied to various types of questionnaires. As an example, a psychological test is given intended to provide support to women during pregnancy and the postpartum period who may have some specific psychological problems. The use case diagram of the service is given in Figure 3 and its realization in Figure 4. The text data that users enter is in a format that is not suitable for direct processing and needs to be processed using NLP techniques to be machine-readable. Descriptions of stressful situations are compared with those in the database, to obtain the results of the questionnaire. To compare descriptions as word vectors, their pre-processing and normalization are required [5]. 


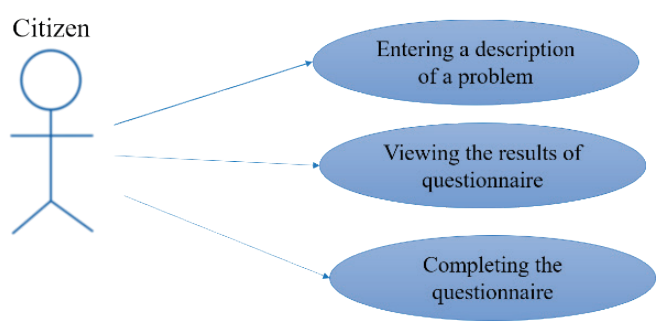

Figure 3. Use case diagram for the service for automatic processing of questionnaires

\section{Psihološki testovi}

\begin{tabular}{l} 
Test na postporođajnu depresiju \\
Molim Vas označite odgovore koji najbolje opisiju kako ste se osećali proteklih 7 dana, \\
a ne samo kako se osećate danas. \\
U poslednjih sedam dana: \\
\hline 1. Mogla sam se smejati i videti smešnu stranu stvari \\
OKao i inače \\
ONe tako često \\
OSigurno manje nego inače \\
ONe uopšte \\
\hline 2. Radovala sam se stvarima unapred: \\
OKao i inače \\
ONe tako često \\
OSigurno manje nego inače \\
OJedva \\
\hline
\end{tabular}

Figure 4. The realization of service for automatic processing of psychological tests

\subsection{DASHBOARDS WITH INFORMATION ABOUT AN EPIDEMIC}

At the time of an epidemic, people need to have information about the situation in their place from verified sources, to act following it. The lack of such information can lead to the spread of news from non-objective sources, unscrupulous behavior of citizens, but also the spread of panic. Epidemic control is one of the topics in the field of smart health within smart cities. Based on the reports that are stored daily in medical information systems, various information on the epidemiological situation in cities can be extracted. Examples of realization are given based on EHRs from Health Centre Nis, from the period of the measles epidemic. The service is designed to work in real-time, directly takes data from EHRs, and provides many details, such as the prevalence of the virus by age structure, health facilities, and an overview of the number of infected in the appropriate time interval [15] [16] [17]. This service enables two functionalities based on NLP techniques (Figure 5): a) Report on the most common symptoms. Using this report, the citizen would be more informed about the disease and could recognize the symptoms and in that case, contact a doctor. This report is created based on data obtained by entering in an unstructured field for physician comments from EHRs. With adequate processing of this text, frequently occurred symptoms can be extracted and shown on the diagram (Figure 6).

b) Questionnaire on the patient's current health condition (symptom presence/absence) to check whether to report to the medical station for treatment or not.

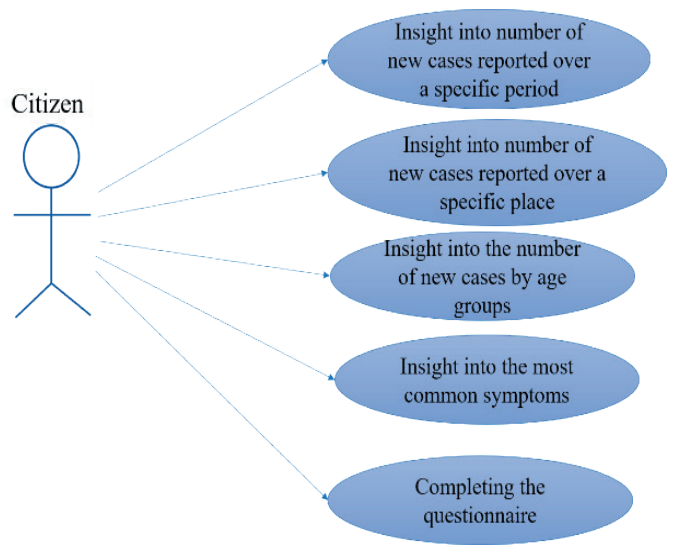

Figure 5. Use case diagram for the service for visualization of the epidemic data



Figure 6. The realization of service with information about epidemy 


\section{CONCLUSION}

A lot of textual data is created daily in medical information systems, and NLP techniques can be applied to gain new knowledge that will be used to create smart health services. Three use cases of NLP-based smart health services for each input type of text data (document, EHRs, and patient's responses) are presented. In further research, we will improve these and create new services that use NLP methods, such as finding and correcting errors when entering a non-structural part in the EHRs.

\section{ACKNOWLEDGEMENTS}

This paper is partially supported by the Ministry of Education, Science and Technological Development of the Republic of Serbia under projects III44007 and ON 174026.

\section{REFERENCES}

[1] S. P. Mohanty, U. Choppali and E. Kougianos, "Everything you wanted to know about smart cities: The Internet of things is the backbone," IEEE Consumer Electronics Magazine, vol. 5, no. 3, pp. 60-70, 2016.

[2] M. S. Mahmud, J. Z. Huang, S. Salloum, T. Z. Emara and K. Sadatdiynov, "A survey of data partitioning and sampling methods to support big data analysis," Big Data Mining and Analytics, vol. 3, no. 2, p. 85-101, 2020.

[3] H. Lu, P.-H. Ho and M. Guizani, "Guest editorial: Special issue on internet of things for industrial security for smart cities," IEEE Internet of Things Journal, vol. 8, no. 8, p. 6140-6142, 2021.

[4] A. Avdic, U. Marovac and D. Jankovic, "Smart health services for epidemic control," in 55th ICEST, 2020.

[5] U. Marovac, A. Ljajić, A. Avdić and A. Fazlagić, "Automation of psychological testing of stressful situations in the Serbian," in ICIST, Kopaonik, 2019.

[6] S. Meystre and M. E. f. t. I. Y. S. o. P. Records, "Electronic Patient Records: Some answers to the data representation and reuse challenges: Findings from the section on Patient Records," Yearbook of Medical Informatics, vol. 16, no. 01, p. 47-48, 2007.

[7] D. G. Manogaran, D. H. Qudrat-Ullah and D. Q. Xin, "Special issue on deep structured learning for natural language processing," ACM Transactions on Asian and Low-Resource Language Information Processing, vol. 20, no. 1, p. 1-2, 2021.

[8] J.-C. Kim and K. Chung, "Depression index service using knowledge based crowdsourcing in smart health," Wireless Personal Communications, vol. 93, no. 1, p. 255-268, 2017.
[9] V. Garla, V. L. Re III, Z. Dorey-Stein, F. Kidwai, M. Scotch, J. Womack, A. Justice and C. Brandt, "The Yale cTAKES extensions for document classification: architecture and application," Journal of the American Medical Informatics Association, vol. 18, no. 5, pp. 614-620, 2011.

[10] E. Soysal, J. Wang, M. Jiang, Y. Wu, S. Pakhomov, H. Liu and H. Xu, "CLAMP - a toolkit for eficiently building customized clinical natural language processing pipelines," Journal of the American Medical Informatics Association, vol. 25, no. 3, pp. 331-336, 2018.

[11] D. L. MacLean and J. Heer, "Identifying medical terms in patient-authored text: a crowdsourcingbased approach," Journal of the American Medical Informatics Association, vol. 20, no. 6, pp. 11201127, 2013.

[12] . K. H. Lai, M. Topaz, F. R. Goss and L. Zhou, "Automated misspelling detection and correction in clinical free-text records," Journal of biomedical informatics, vol. 55, pp. 188-195, 2015.

[13] E. Kajan, A. Pljasković and A. Crnišanin, "Normalizacija tekstualnih dokumenata na sprskom jeziku u cilju efikasnijeg pretraživanja u sistemima e-uprave," in ETRAN, Zlatibor, 2012.

[14] "Speech-to-text: Automatic speech recognition," [Online]. Available: https://cloud.google.com/ speech-to-text. [Accessed 6 June 2021].

[15] A. R. Avdić, U. M. Marovac and D. S. Janković, "Smart Health Services for Epidemic Control," in 2020 55th International Scientific Conference on Information, Communication and Energy Systems and Technologies (ICEST), 2020.

[16] A. R. Avdić, U. M. Marovac and D. S. Janković, "Normalization of Health Records in the Serbian Language with the Aim of Smart Health Services Realization," Facta Universitatis, Series: Mathematics and Informatics, pp. 825-841, 2020.

[17] A. Avdić, U. Marovac and D. Janković, "Automated labeling of terms in medical reports in Serbian," Turkish Journal of Electrical Engineering \& Computer Sciences, vol. 28, no. 6, pp. 3285-3303, 2020. 